\title{
Solubility of Pyrene in Ternary Propanol + Butanol + 2,2,4-Trimethylpentane Solvent Mixtures at 299.15 K
}

\author{
Ebun M. Debase and William E. Acree, J r.* \\ Department of Chemistry, University of North Texas, Denton, Texas 76203-5070
}

\begin{abstract}
Experimental solubilities are reported for pyrene dissolved in ternary 1-propanol + 1-butanol $+2,2,4-$ trimethylpentane, 2-propanol + 1-butanol + 2,2,4-trimethylpentane, 1-propanol +2 -butanol + 2,2,4trimethylpentane, and 2-propanol +2 -butanol $+2,2,4$-trimethylpentane solvent mixtures at $26{ }^{\circ} \mathrm{C}$ and atmospheric pressure. Nineteen compositions were studied for each of the four solvent systems. Also measured were the solubilities of pyrene in binary 1-butanol + 2,2,4-trimethylpentane mixtures. Results of these measurements are used to test the predictive ability of the ternary solvent form of the Combined NIBS/Redlich-Kister equation. Computations showed that the model predicted the observed solubility behavior to within an overall average absolute deviation of $\sim 1.6 \%$, which is comparable to the experimental uncertainty of $\pm 1.5 \%$.
\end{abstract}

\section{Introduction}

Solid-liquid equilibrium data of organic nonelectrolyte systems are becoming increasingly important in the petroleum industry, particularly in light of present trends toward heavier feedstocks and the known carcinogenicity/ mutagenicity of many of the larger polycyclic aromatic compounds. Solubility data for a number of polycyclic aromatic hydrocarbons (i.e., anthracene and pyrene) and heteroatom polynuclear aromatics (i.e., carbazole, dibenzothiophene, and xanthene) have been published in the recent chemical literature. For a listing of references see Acree. ${ }^{1-3}$ Despite efforts by experimentalists and scientific organizations, in terms of both new experimental measurements and critically evaluated data compilations, there still exist numerous systems for which solubility data are not readily available.

In the present study pyrene solubilities have been measured in four ternary propanol + butanol $+2,2,4-$ trimethylpentane systems at $(26.0 \pm 0.1){ }^{\circ} \mathrm{C}$. Nineteen ternary compositions were studied for each of the four systems. Also measured were the solubilities of pyrene in binary 1-butanol + 2,2,4-trimethylpentane mixtures. Results of these measurements are used to test the predictive ability of expressions based upon the general mixing model used in deriving the Combined NIBS/Redlich-Kister equation. Subsequent studies will interpret the measured pyrene solubilities using both Mobile Order Theory and the Kretschmer-Wiebe association model. Powell et al. ${ }^{4}$ and McHale et al. ${ }^{5}$ showed that these latter two solution models provided reasonably accurate descriptions for the sol ubility behavior of pyrene and anthracene in binary alkane + alcohol and alcohol + alcohol solvent mixtures. Neither model has been used to describe solubility in ternary solvent systems.

\section{Experimental Methods}

Pyrene (Aldrich, 98\%) was recrystallized three times from anhydrous methanol. 1-Propanol (Aldrich, 99+\%,

* Author to whom correspondence should be addressed [e-mail acree@unt.edu; fax (940) 565-4318]. anhydrous), 2-propanol (Aldrich, 99+\%, anhydrous), 1-butanol (Aldrich, HPLC, 99.8+\%), 2-butanol (Aldrich, 99+\%, anhydrous), and 2,2,4-trimethylpentane (Aldrich, 99.8\%, anhydrous) were stored over molecular sieves and distilled shortly before use. Gas chromatographic analysis showed solvent purities to be $\geq 99.7 \mathrm{~mol} \%$. Binary and ternary solvent mixtures were prepared by mass so that compositions could be calculated to 0.0001 mole fraction. Samples were allowed to equilibrate at $(299.15 \pm 0.1) \mathrm{K}$ for a minimun of 3 days. Aliquots of the saturated sol utions were then withdrawn for spectroscopic analysis at $372 \mathrm{~nm}$ using a Bausch and Lomb Spectronic 2000 spectrophotometer. The methods of sample equilibration and spectrophotometric analysis are discussed in greater detail in an earlier paper. ${ }^{6}$ Experimental pyrene solubilities in the four propanol + butanol +2,2,4-trimethylpentane solvent mixtures are listed in Table 1. The mole fraction solubilities of pyrene in the 1-butanol + 2,2,4-trimethylpentane sub-binary system are presented in Table 2. Numerical values represent the average of between four and eight independent determinations, with the measured values being reproducible to within $\pm 1.5 \%$.

\section{Results and Discussion}

Acree and co-workers ${ }^{7-9}$ suggested the Combined NIBS/ Redlich-Kister equation for the mathematical representation of isothermal solubility data in binary solvent systems

$$
\begin{array}{r}
\ln x_{A}^{\text {sat }}=x_{B}^{0} \ln \left(x_{A}^{\text {sat }}\right)_{B}+x_{C}^{0} \ln \left(x_{A}^{\text {sat }}\right)_{C}+ \\
\qquad x_{B}^{0} x_{C}^{0} \sum_{i=0}^{N} S_{i}\left(x_{B}^{0}-x_{C}^{0}\right)^{i}
\end{array}
$$

where $x_{B}^{0}$ and $x_{C}^{0}$ refer to the initial mole fraction composition of the binary solvent calculated as if the solute were not present and $\left(x_{A}^{\text {sat }}\right)_{i}$ denotes the measured solute solubility in pure solvent $i$. The various $S_{i}$ curve-fit parameters can be evaluated with a least-squares analysis. Equation 1 has been shown to provide very accurate mathematical representations of anthracene, pyrene, and carbazole solubilities in a large number of both complexing and noncom- 
Table 1. Experimental Mole Fraction Solubilities of Pyrene $\left(x_{A}^{\text {sat }}\right)$ in Ternary Propanol (B) + Butanol (C) + 2,2,4-Trimethylpentane (D) Solvent Mixtures at 299.15 K

\begin{tabular}{|c|c|c|c|c|c|}
\hline$x_{B}^{0}$ & $x_{C}^{0}$ & $x_{A}^{\text {sat }}$ & $x_{B}^{0}$ & $x_{C}^{0}$ & $x_{A}^{\text {sat }}$ \\
\hline \multicolumn{6}{|c|}{ 1-Propanol (B) 1-Butanol (C) + 2,2,4-Trimethylpentane (D) } \\
\hline 0.4337 & 0.3632 & 0.00661 & 0.2562 & 0.2094 & 0.00781 \\
\hline 0.1954 & 0.7132 & 0.00653 & 0.7831 & 0.1395 & 0.00528 \\
\hline 0.3581 & 0.2965 & 0.00709 & 0.6042 & 0.2581 & 0.00584 \\
\hline 0.3244 & 0.5305 & 0.00661 & 0.1896 & 0.2805 & 0.00792 \\
\hline 0.7957 & 0.1003 & 0.00536 & 0.1432 & 0.7376 & 0.00684 \\
\hline 0.7661 & .1791 & 0.00517 & 0.3384 & 0.1481 & 0.00758 \\
\hline 0.2455 & 0.6917 & 0.00638 & 0.1596 & 0.4958 & 0.00770 \\
\hline 0.1611 & 0.5824 & 0.00732 & 0.5475 & 0.1267 & 0.00653 \\
\hline 0.4596 & 0.4840 & 0.00580 & 0.6513 & 0.1161 & 0.00616 \\
\hline 0.5712 & 0.3729 & 0.00551 & & & \\
\hline \multicolumn{6}{|c|}{ 2-Propanol (B) + 1-Butanol (C) + 2,2,4-Trimethylpentane (D) } \\
\hline 0.3918 & 0.3835 & 0.00596 & 0.2550 & 0.2061 & 0.00748 \\
\hline 0.1 & 0.7216 & 0.0 & 0.7777 & 0.1382 & 0.0 \\
\hline 0.3640 & 0.3114 & 0.00654 & 0.6063 & 0.2474 & 0.00498 \\
\hline 0.3236 & 0.5234 & 0.00606 & 0.1768 & 0.2812 & 0.00771 \\
\hline 0.7 & 0.0970 & 0.00419 & 0.1364 & 0.7433 & 0.00650 \\
\hline 0.7 & 0.1826 & 0.0 & 0.3285 & 0.1 & 0.0 \\
\hline 0.2 & 0.7010 & 0.0 & 0.1608 & 0.4971 & 0.00730 \\
\hline 0.1507 & 0.5985 & 0.00699 & 0.5479 & 0.1281 & 0.00592 \\
\hline 0.4519 & 0.4870 & 0.00507 & 0.6421 & 0.1195 & 0.00521 \\
\hline 0.5603 & 0.3834 & 0.00458 & & & \\
\hline \multicolumn{6}{|c|}{ 1-Propanol (B) + 2-Butanol (C) + 2,2,4-Trimethylpentane (D) } \\
\hline 0.4351 & 0.3621 & 0.00581 & 0.2627 & 0.2108 & 0.00738 \\
\hline 0.2009 & 0.7124 & 0.00511 & 0.7883 & 0.1359 & 0.00492 \\
\hline 0.3685 & 0.3007 & 0.00650 & 0.6038 & 0.2523 & 0.00544 \\
\hline & & & 0.1756 & 0.2 & 0.00750 \\
\hline & 0. & & 0.1 & 0.7 & 0.0 \\
\hline 0. & 0.1830 & 0.00 & 0.3489 & 0.1292 & 0.00725 \\
\hline 0.2 & 0.6924 & 0.00 & 0.1669 & 0.4869 & 0.00671 \\
\hline & 0.5 & & 0.5649 & 0.1134 & 0.00640 \\
\hline & 0. & 0.0 & 0.6598 & 0.1033 & 0.00593 \\
\hline 0.5737 & & 0.00479 & & & \\
\hline \multicolumn{6}{|c|}{ 2-Propanol (B) + 2-Butanol (C) + 2,2,4-Trimethylpentane (D) } \\
\hline 0.4306 & 0.3642 & 0.00523 & 0.2544 & 0.2113 & 0.00704 \\
\hline & 0.7210 & 0.00 & 0.7782 & 0.1440 & 0.00387 \\
\hline & 0.2972 & & 0.6006 & 0.2592 & 0.00464 \\
\hline & & & 0.1811 & 0.2 & 0.00714 \\
\hline 0.7 & 0.1024 & 0.00 & 0.1420 & 0.7372 & 0.00511 \\
\hline 0.7705 & 0.1780 & 0.00367 & 0.3332 & 0.1459 & 0.00680 \\
\hline 0.24 & 0.7056 & 0.00442 & 0.1607 & 0.4922 & 0.00657 \\
\hline & & 0.0 & 0.5 & 0.1 & 0.00 \\
\hline & 0.4747 & 0.00409 & 0.6505 & 0.1106 & 0.00504 \\
\hline 0.5 & 0.3 & 0.00 & & & \\
\hline
\end{tabular}

Table 2. Experimental Mole Fraction Solubilities of Pyrene $\left(x_{A}^{\text {sat }}\right)$ in Binary 1-Butanol (B) +

2,2,4-Trimethylpentane Mixtures at $299.15 \mathrm{~K}$

\begin{tabular}{cccccc}
\hline$x_{B}^{0}$ & $x_{A}^{\text {sat }}$ & $x_{B}^{0}$ & $x_{A}^{\text {sat }}$ & $x_{B}^{0}$ & $x_{A}^{\text {sat }}$ \\
\hline 0.0000 & 0.00720 & 0.5407 & 0.00817 & 0.8832 & 0.00716 \\
0.2001 & 0.00848 & 0.6409 & 0.00806 & 0.9334 & 0.00687 \\
0.3122 & 0.00849 & 0.7307 & 0.00779 & 1.0000 & 0.00622
\end{tabular}

plexing solvent mixtures. ${ }^{1-3} \mathrm{~J}$ ouyban-Gharamaleki and coworkers ${ }^{10-13}$ successfully used the volume fraction, $\phi_{\mathrm{i}}$, modification of eq 1

$$
\begin{aligned}
\ln x_{A}^{\text {sat }}=\phi_{B}^{0} \ln \left(x_{A}^{\text {sat }}\right)_{B}+\phi_{C}^{0} \ln \left(x_{A}^{\text {sat }}\right)_{C}+ & \\
& \phi_{B}^{0} \phi_{C}^{0} \sum_{i=0}^{N} S_{i}\left(\phi_{B}^{0}-\phi_{C}^{0}\right)^{i}
\end{aligned}
$$

to describe the solubility behavior of various drug molecules in binary aqueous-organic solvent mixtures. In the pharmaceutical industry, researchers often express the solvent composition in terms of volume fractions rather than in terms of mole fractions. In the case of structurally similar drug molecules the numerical values of the $S_{i}$ coefficients
Table 3. Summarized Comparison between Observed Pyrene Solubilities in Ternary Propanol + Butanol + 2,2,4-Trimethylpentane Solvent Mixtures and Predicted Values Based upon the Combined NIMS/Redlich-Kister

\begin{tabular}{|c|c|c|}
\hline ternary solvent mixture & $\%$ deva $^{a}$ & $\mathrm{dev}^{b}$ \\
\hline $\begin{array}{c}\text { 1-propanol (B) + 1-butanol (C) + } \\
\text { 2,2,4-trimethylpentane (D) }\end{array}$ & 1.66 & 0.00210 \\
\hline $\begin{array}{c}\text { 2-propanol (B) + 1-butanol (C) }+ \\
\text { 2,2,4-trimethylpentane (D) }\end{array}$ & 1.42 & 0.00190 \\
\hline $\begin{array}{c}\text { 1-propanol (B) + 2-butanol (C) }+ \\
\text { 2,2,4-trimethylpentane (D) }\end{array}$ & 1.69 & 0.00146 \\
\hline $\begin{array}{c}\text { 2-propanol }(B)+2 \text {-butanol }(C)+ \\
\text { 2,2,4-trimethylpentane (D) }\end{array}$ & 1.62 & 0.00147 \\
\hline
\end{tabular}
Equation 3

a Deviation $(\%)=(100 / N) \sum\left|\left[\left(x_{A}^{\text {sat }}\right)^{\text {calcd }}-\left(x_{A}^{\text {sat }}\right)^{\text {expt }}\right] /\left(x_{A}^{\text {sat }}\right)^{\text {expt } 1}\right|$, where $\mathrm{N}$ corresponds to the number of data points for each ternary system. In the present study, solubilities were determined at 19 different ternary solvent compositions. ${ }^{b}$ Deviation $=\Sigma \mid\left(x_{A}^{\text {sat }}\right)$ calcd $\left.-\left(x_{A}^{\text {sat }}\right)^{\text {exptl }}\right]$.

were found to be nearly constant in a given binary solvent mixture. ${ }^{10}$

For a ternary solvent system, the mathematical representation takes the form of

$$
\begin{array}{r}
\ln x_{A}^{\text {sat }}=x_{B}^{0} \ln \left(x_{A}^{\text {sat }}\right)_{B}+x_{C}^{0} \ln \left(x_{A}^{\text {sat }}\right)_{C}+x_{D}^{0} \ln \left(x_{A}^{\text {sat }}\right)_{D}+ \\
x_{B}^{0} x_{C}^{0} \sum_{i=0}^{r} S_{i, B C}\left(x_{B}^{0}-x_{C}^{0}\right)^{i}+x_{B}^{0} x_{D}^{0} \sum_{j=0}^{s} S_{j, B D}\left(x_{B}^{0}-x_{D}^{0}\right)^{j}+ \\
x_{C}^{0} x_{D}^{0} \sum_{k=0}^{t} S_{k, C D}\left(x_{C}^{0}-x_{D}^{0}\right)^{k}
\end{array}
$$

Recent studies have shown that eq 3 provides reasonably accurate predictions for anthracene solubilities in ternary two alkane + alcohol $^{14,15}$ and alkane + two alcohol ${ }^{16-18}$ solvent mixtures. Such systems exhibit fairly large deviations from solution ideality arising from the self-association of each alcohol cosolvent and, in mixtures containing two alcohol cosolvents, from the formation of heterogeneous hydrogen-bonded chains between dissimilar alcohol molecules.

The predictive ability of eq 3 is summarized in Table 3 for pyrene dissolved in the four propanol + butanol + 2,2,4trimethylpentane systems. Published papers ${ }^{19-21}$ have reported the cal culated $S_{i}$ parameters for pyrene dissolved in seven of the eight sub-binary solvent systems. Solubility data for the remaining binary solvent system were measured as part of the present study. We have determined the numerical values of the $S_{i}$ parameters for the binary 1-butanol + 2,2,4-trimethylpentane solvent system by curve fitting the experimental pyrene mole fraction solubility data in Table 2 in accordance with the polynomial form of eq 1

$$
\begin{aligned}
{\left[\ln x_{A}^{\text {sat }}-x_{B}^{0} \ln \left(x_{A}^{\text {sat }}\right)_{B}-\right.} & \left.x_{C}^{0} \ln \left(x_{A}^{\text {sat }}\right)_{C}\right] /\left(x_{B}^{0} x_{C}^{0}\right)= \\
& S_{0}+S_{1}\left(x_{B}^{0}-x_{C}^{0}\right)+S_{2}\left(x_{B}^{0}-x_{C}^{0}\right)^{2}
\end{aligned}
$$

using the commercial software TableCurve ( andel Scientific, Corte Madera, CA). Equation 1 back-calculates the experimental pyrene solubilities in the binary 1-butanol + 2,2,4-trimethylpentane system to within an overall average deviation of $\pm 0.3 \%$. Numerical values of the $S_{i}$ parameters are presented in Table 4 for convenience. Experimental mole fraction solubilities in 1-propanol $\left(x_{A}^{\text {sat }}\right.$ $=0.00426)$, 2-propanol $\left(x_{A}^{\text {sat }}=0.00290\right)$, 1-butanol $\left(x_{A}^{\text {sat }}=\right.$ $0.00622)$, 2-butanol ( $\left.x_{A}^{\text {sat }}=0.00439\right)$, and 2,2,4-trimethylpentane $\left(x_{A}^{\text {sat }}=0.00720\right)$ were also taken from the chemi- 
1466 J ournal of Chemical and Engineering Data, Vol. 46, No. 6, 2001

Table 4. Combined NIBS/Redlich-Kister Parameters Calculated from Pyrene Solubilities in the Sub-binary Solvent Systems

\begin{tabular}{cc}
\hline solvent (B) + solvent (C) & $\mathrm{S}_{\mathrm{i}}{ }^{\mathrm{a}}$ \\
\hline 2-propanol (B) + 2,2,4-trimethylpentane (C) & 1.329 \\
& 0.232 \\
& 0.378 \\
2-butanol (B) + 2,2,4-trimethylpentane (C) & 1.148 \\
& 0.274 \\
1-propanol (B) + 2,2,4-trimethylpentane (C) & 0.558 \\
& 0.864 \\
& 0.255 \\
1-butanol (B) + 2,2,4-trimethylpentane (C) & 0.304 \\
& 0.826 \\
& -0.105 \\
1-propanol (B) + 1-butanol (C) & 0.875 \\
2-propanol (B) + 1-butanol (C) & 0.127 \\
1-propanol (B) + 2-butanol (B) & -0.065 \\
2-propanol (B) + 2-butanol (C) & 0.215 \\
& none \\
\end{tabular}

a Combined NIBS/Redlich-Kister curve-fit parameters are ordered as $\mathrm{S}_{0}, \mathrm{~S}_{1}$, and $\mathrm{S}_{2} .{ }^{\mathrm{b}}$ Experimental solubility data accurately described without the use of the $S_{i}$ curve-fit parameters.

cal literature. ${ }^{19-22}$ Examination of the numerical entries in Table 3 reveals that eq 3 predicts the solubility of pyrene to within an overall average absolute deviation of $1.6 \%$, which is comparable to the experimental uncertainty of $\pm 1.5 \%$. For the four systems studied, eq 3 was found to provide very accurate predictions of the observed solubility behavior.

\section{Literature Cited}

(1) Acree, W. E., J r. Polycyclic Aromatic Hydrocarbons in Pure and Binary Solvents; IUPAC Solubility Data Series 54; Oxford University Press: Oxford, U.K., 1994

(2) Acree, W. E., J r. Polycyclic Aromatic Hydrocarbons: Binary Nonaqueous Systems: Part 1 (Solutes A-E); IUPAC Solubility Data Series 58; Oxford University Press: Oxford, U.K., 1995.

(3) Acree, W. E., J r. Polycyclic Aromatic Hydrocarbons: Binary Nonaqueous Systems: Part 2 (Solutes F-Z); IUPAC Solubility Data Series 59; Oxford University Press: Oxford, U.K., 1995.

(4) Powell, J R.; McHale, M. E. R.; Kauppila, A.-S. M.; Acree, W. E., J r.; Flanders, P. H.; Varanasi, V. G.; Campbell, S. W. Prediction of Anthracene Solubility in Alcohol + Alkane Solvent Mixtures Using Binary Alcohol + Alkane VLE Data. Comparison of Kretschmer-Wiebe and Mobile Order Models. Fluid Phase Equilib. 1994, 134, 185-200.

(5) McHale, M. E. R.; Zvaigzne, A. I.; Powell, J . R.; Kauppila, A.-S. M.; Acree, W. E., I r.; Campbell, S. W. Thermochemical Investigations of Hydrogen-Bonded Solutions. Part 9. Comparison of Mobile Order Theory and the Kretschmer-Wiebe Association Model for Predicting Pyrene Solubilities in Binary Alcohol + Alcohol Solvent Mixtures. Phys. Chem. Liq. 1996, 32, 67-87.
(6) McHale, M. E. R.; Coym, K. S.; Fletcher, K. A.; Acree, W. E., J r Solubility of Pyrene in Binary Alcohol + 2-Methyl-2-butano Solvent Mixtures at 299.2 K. J . Chem. Eng. Data 1997, 42, 511513.

(7) Acree, W. E., J r. Mathematical Representation of Thermodynamic Properties. Part 2. Derivation of the Combined Nearly Ideal Binary Solvent (NIBS)/Redlich-Kister Mathematical Representation from a Two-Body and Three-Body Interactional Mixing Model. Thermochim. Acta 1992, 198, 71-79.

(8) Acree W. E . J r. Zvaigzne A. I. Thermodynamic Properties of Nonelectrolyte Solutions. Part 4. Estimation and Mathematical Representation of Solute Activity Coefficients and Solubilities in Binary Solvents Using the NIBS and Modified Wilson Equations. Thermochim. Acta 1991, 178, 151-167.

(9) Acree, W. E., J r.; McCargar, J. W.; Zvaigzne, A. I.; Teng, I.-L. Mathematical Representation of Thermodynamic Properties. Carbazole Solubilities in Binary Alkane + Dibutyl Ether and Alkane + Tetrahydropyran Solvent Mixtures. Phys. Chem. Liq. 1991, 23, 27-35.

(10) J ouyban-Gharamaleki, A.; Clark, B. J .; Acree, W. E.,J r. Prediction of Drug Solubility in Ternary Solvent Mixture. Drug Dev. Ind. Pharm. 2000, 26, 971-973.

(11) J ouyban-Gharamaleki, A.; Acree, W. E., J r. Comparison of Models for Describing Multiple Peaks in Solubility Profiles. Int. J . Pharm 1998, 167, 177-182.

(12) J ouyban-Gharamaleki, A.; Hanaee, J. A Novel Method for Improvement of the CNIBS/R-K Equation. Int. J . Pharm. 1997, 154, 243-245.

(13) J ouyban-Gharamaleki, A.; Barzegar-J alali, M.; Acree, W. E., J r. Solubility Correlation of Structurally Related Drugs in Binary Solvent Mixtures. Int. J . Pharm. 1998, 166, 205-209.

(14) Deng, T.; Acree, W. E., J r. Solubility of Anthracene in Ternary Propanol +2,2,4-Trimethylpentane + Cyclohexane and Butano + 2,2,4-Trimethylpentane + Cyclohexane Solvent Mixtures. J. Chem. Eng. Data 1998, 43, 1059-1061.

(15) Deng, T.; Hernández, C. E.; Roy, L. E.; Acree, W. E., J r. Solubility of Anthracene in Ternary (Propanol + Heptane + Cyclohexane) and (Butanol + Heptane + Cyclohexane) Solvent Mixtures. J. Chem. Thermodyn. 1999, 31, 205-210.

(16) Deng, T.; Acree, W. E., J r. Solubility of Anthracene in Ternary Propanol + Butanol + Cyclohexane Solvent Mixtures. J. Chem Eng. Data 1998, 43, 1062-1064.

(17) Deng, T.; Childress, S. D.; De Fina, K. M.; Sharp, T. L.; Acree, W. E., J r. Solubility of Anthracene in Ternary Propanol + Butano $+2,2,4-$ Trimethyl pentane Solvent Mixtures. J . Chem. Eng. Data 1998, 43, 1065-1067.

(18) Deng, T.; Childress, S. D.; De Fina, K. M.; Acree, W. E., J r. Solubility of Anthracene in Ternary Propanol + Butanol + Heptane Solvent Mixtures. Chem. Eng. Commun. 1999, 172, 217224.

(19) Zvaigzne, A. I.; Acree, W. E., J r. Solubility of Pyrene in Binary Alkane + 1-Propanol and Alkane + 2-Propanol Solvent Mixtures. . Chem. Eng. Data 1993, 38, 393-395.

(20) Hernández, C. E.; Coym, K. S.; Roy, L. E.; Powell, J . R.; Acree, W. E., J r. Solubility of Pyrene in Binary (Alkane + 2-Butanol) Solvent Mixutres. J. Chem. Thermodyn. 1998, 30, 37-42.

(21) Zvaigzne, A. I.; Miller, B. J .; Acree, W. E.,J J. Solubility of Pyrene in Binary Alcohol + 1-Propanol and Alcohol + 2-Propanol Solvent Mixtures. J . Chem. Thermodyn. 1995, 40, 1267-1269.

Received for review May 2, 2001. Accepted J uly 16, 2001.

J E101449 